International Business Management 6(1): 17-21, 2012

ISSN: $1993-5250$

(C) Medwell Journals, 2012

\title{
Role of Adolescent's Personality in Parent Consumer Socialization
}

\author{
${ }^{1}$ Maisarah Ahmad, ${ }^{2}$ Roziah Sidik Mat Sidek and ${ }^{3}$ Wan Kamal Mujani \\ ${ }^{1}$ School of Management, Faculty of Economics and Management, \\ ${ }^{2}$ Department of Arabic Studies and Islamic Civilization, Faculty of Islamic Studies, \\ ${ }^{3}$ Institute of West Asian Studies (IKRAB), Universiti Kebangsaan Malaysia, \\ 43600 Bangi, Selangor, Malaysia
}

\begin{abstract}
This study extends the explanation of consumer socialization theory to parents using mothers as proxy. Elements of personality are incorporated (operationalized as adolescent socialization types) to isolate the pertinent adolescent socialization types that discern the highly-from lowly consumer socialized mothers. Via binary logistic regression analysis, findings from adolescents' perspective revealed that the most discerning traits that differentiate the highly consumer socialized mothers from the least consumer socialized mothers are the adolescents' levels of agreeableness and need for body resources. On the contrary, mother's were not susceptible to any of the adolescent personality traits.
\end{abstract}

Key words: Family decision making, consumer socialization, personality traits, $3 \mathrm{M}$ model of motivation and personality, mothers, parents

\section{INTRODUCTION}

Traditionally, both marketers and consumer researchers have side-lined children as a consumer segment because of their miniscule disposable income. Since, the 1980 s interest has been growing in children's consumption behavior, especially their influence in family consumption decisions. In the late $70 \mathrm{~s}$ and the early $80 \mathrm{~s}$, children's acquisition of consumer related skills, knowledge and attitude was posited to subsume under the theory of consumer socialization (Ward, 1974). Ever since, the inception of the consumer socialization theory, research on consumer socialization has evolved to include areas such as children's influence in family purchase decisions.

Children in family decision making: From the theoretical perspective including children as a decision role will help researchers fully understand family consumer behavior. Past research has opened an avenue but more effort is needed to further the stream. From the managerial perspective, given children's growing consumption power (McNeal, 1998), understanding children's influence would help practitioners better serve the child consumer segment.

Carlson and Grossbart (1988) investigated on parental socialization type which is similar to parents' personality in relations to imparting consumer socialization skills to their children. According to them parental socialization type (parental style) provides a theoretical basis for explaining differences among parents regarding how they communicate consumer skills and knowledge to their children. Whether parents opt for an authoritative, strict or protective approach, children are socialized by different parenting personality traits. However as of yet, no empirical attempts have looked into the children personality traits in relation to children imparting and sharing their knowledge and skills of consumer behavior to and with their parents.

Personality and marketing: Personality variables have a long history of study in the marketing literature and have been applied both to segmentation decisions and to message construction and consumers espouse issues. However, the use of personality traits in marketing studies has not been without criticism. Of particular concern for researchers is the ability of personality research to account for significant variance in actual behaviour. In addition, Plummer (2000) recently discussed a number of other concerns regarding personality research including the search for a working definition of exactly what personality is the proliferation of personality batteries, scale reliability concerns and lack of solid theoretical personality bases for segmentation.

Despite these concerns many researchers have found that considerable insight can be gained by examining the

Corresponding Author: Wan Kamal Mujani, Institute of West Asian Studies (IKRAB), Universiti Kebangsaan Malaysia, 43600 Bangi, Selangor, Malaysia 
role of personality in marketing. Mowen (2000) developed a marketing-based personality theory called $3 \mathrm{M}$ Model which can account up to $22 \%$ variance solely on the basic psychological traits as predictors of consumer behavior. In addition, Wansink and Park demonstrated how personality variables can be used to describe and to discriminate among segments of heavy and light users of products. The trait of connectedness-separateness has been shown to moderate responses to advertisements. Earlier, Schaninger and Sciglimpaglia explored the association of ambiguity and self-esteem with demographics and socio-economic factors in the process of information acquisition.

LaBarbera and other researchers found that advertisements may have greater appeal when advertising visuals are consistent with consumer personality processing style. Stephenson and other researchers investigated how dimensions of sensation seeking influence adolescent responses to anti-drug public service announcements. Aaker demonstrated how personality theory may be applied in branding decisions, suggesting that consumers perceive brands as possessing characteristics of the human personality. Mooradian assessed the effects of extraversion and neuroticism on advertising responses.

Several other studies have introduced new individual difference constructs into the marketing literature that have value for promotional research including consumer bargaining proneness and frugality (thriftiness), value consciousness, materialism and risk aversion and compulsive consumption.

According to Eysenck (1991), personality is a predictor of social behavior (e.g., decision-making). In tandem, L.B. Blue found that there are correlations between personalities and influence strategies in college business students and business professionals as well as personality traits and choice strategy behavior (Horton, 1979). While Webster (2000) calls for investigation of personality in family decision making. Ghani and Zain (2004) found a significant relationship between children personality traits and consumer socialization outcome in her exploratory study. In addition, Bearden and Rose (1990) found that a person who has a low tendency to conform (a personality trait based on Attention to Social Comparison scale-ATSCI) will tend to make her desired purchases when she is shopping alone rather than with a group.

Meta-theoretical Model of Motivation and Personality (the 3M Model): The $3 \mathrm{M}$ Model proposes that traits are represented at one of four levels, elemental traits, compound traits, situational traits and surface traits.
Hierarchical models of personality traits have been proposed previously are all from psychological standpoint. For example, Allport (1961) identified three levels of traits, namely cardinal, central and surface with each level having an increased intensity of effect on behavior. On the other hand, Mowen's Model, developed in the context of consumer behavior setting has higher relevancy in consumer behavior studies than other personality models.

Similar to Carlson and Grossbart's attempt in delineating parenting style via the utilization of Baumrind's parental style study in psychological setting (parents' personality in imparting values, attitude and behavior in the context of general socialization) this present research will focus only on the 3M Model's elemental traits in developing adolescent socialization types.

Theoretical framework and hypotheses; Adolescent: Adolescent is defined as the involvement of adolescent as a means in mothers' acquisition of skills and knowledge related to consumer behavior. Adolescent as socialization agent is operationalized into eight dimensions of adolescent socialization types. Adapting from Mowen (2000)'s 3M Model and Carlson and Grossbart (1988)'s parental socialization types, the construct adolescent is operationalized into adolescent socialization types.

Early research on consumer socialization examined the social factors (parents, peers and mass media) on the consumer behaviour of children and adolescents (Ward, 1974). In addition, previous studies have identified four main socialization agents, i.e., family influence-using parents as the proxy for the consumer socialization agent or source of influence; mass media influence-interface frequency with the television, radio and newspaper; school influence-the extent of consumerism taught and incorporated in the school curricula and peer influencethe extent of children interaction with their peers in moulding the children's consumer socialization outcome (Moschis and Churchill, 1978).

Moschis (1987) challenged the view of restricting consumer socialization process to only the adolescenthood life cycle and asserted that consumer socialization from the social interaction perspective should persist throughout one's lifetime. Reciprocal socialization and resource theory asserts that children can be the agent of socialization because of bidirectional interaction with their parents.

Furthermore based on resource theory, children also gain their leverage in influencing their parents through their personal resources. Radke-Yarrow et al. (1983) 
purport that children dispositions may affect children's socialization outcome. In this study, eight dimensions are incorporated into the adolescent construct. These eight dimensions are similar to Carlson and Grossbart (1988)'s parent socialization type concept. Adapted from Mowen's $3 \mathrm{M}$ Model elemental traits, the eight dimensions are as follow extraversion-tendency to be sociable, out-going and risk-taker conscientiousness-responsible and well organized openness to experience or creativity broad interest and imaginative emotional instability or neuroticism sensitive and emotional agreeableness compassionate, good-natured, eager to cooperate and dislike conflict need for body resources which is an enduring desire to enhance and protect one's own physical resources need for material resources which is an enduring desire to enhance and protect material items and need for arousal which is an enduring desire for stimulation (Licata et al., 2003).

Additionally, Bosnjak et al. (2007) adapted the traits of $3 \mathrm{M}$ Model of Motivation and Personality in successfully identifying the personality determinants of online shopping.

Parent Consumer Socialization Outcome (PCSO): Outcome is the last element in Moschis and Churchill (1978)'s consumer socialization framework. Parent consumer socialization outcome refers to the learning properties (both cognitions and behaviors) a parent develops through socialization including a wide variety of consumer skills, knowledge and attitudes. This construct is operationalized into eight items. This study combines children's influence on familial decision making and consumption related preferences rather than just focusing on a specific product from a specific product category thus, enhancing the robustness of this dependent construct.

To measure consumer socialization outcome of parent's perceptions of parents' susceptibility to children's influence across various decision making stages and consumption related preferences (reciprocal socialization) are operationalized as the items. The items are adapted from Viswanathan et al. (2000) intergenerational influence study (four items) and Swinyard and Sim (1987)'s and Moschis and Mitchell (1986)'s children's influence across four-stages of decision making: problem recognition information search, final decision and actual purchase.

Therefore, it is hypothesized that $\mathrm{H}_{\text {study }}$ Highly consumer socialized mothers are differentiated from lowly consumer socialized mothers by adolescent socialization types, i.e., extraversion, conscientiousness, openness to experience or creativity, emotional instability or neuroticism, agreeableness, need for body resources, need for material resources and/or need for arousal.

\section{MATERIALS AND METHODS}

Data collection and characteristics of respondents: $A$ total of 500 set of questionnaires were group administered to students and another 500 sets were given to mothers through their children. Secondary schools and university students were judgmentally selected because their age group criterion tallied with the study's scope 13-18 years old (Moschis and Churchill, 1978). The selected students were then given a study packet containing a cover letter and a set of mother and adolescent questionnaires.

After screening for missing data, univariate and multivariate outliers, only univariate outliers are identified in both data sets. Since, adolescent outliers do not correspond with the mother's, a total of 15 responses were taken out from the data sets. In the end, out of the 279 usable sets of mother-adolescent responses, only 264 are statistically usable.

Demographic distribution: For the mothers' data set in terms of age, the majority age cohort is $40-44$ years $(36 \%)$, followed by $45-49$ years $(26.1 \%)$ and $35-39$ years $(15.9 \%)$. Malay constituted the largest ethnic group which is $75.8 \%$ (200) of the total respondents. On education level, majority $(54.55 \%)$ are secondary school leavers and more than half (48.95\% full timers and $6.5 \%$ part-timers) are working mothers. About 69 out of 264 mothers have three children where the eldest child is between the ages of $16-20$ years old $(43.2 \%)$ and the youngest is between 11-15 years old $(37.9 \%)$. These ladies are still married $(92.8 \%)$, dominantly speak Malay in their household (73.1\%) and currently live with their children and husband $(78 \%)$. Majority of the household, earn a monthly income bracket of $<\mathrm{RM} 5,000 \quad(67.4 \%)$. The corresponding adolescents' data set revealed majority of them is 15 years of age (26.9\%). Out of 264 adolescents, 107 are males and currently are attending secondary school (71.2\%).

\section{RESULTS AND DISCUSSION}

Adolescent data were run using binary logistic regression to address the study hypothesis. The Hosmer and Lemeshow test produced a $\mathrm{p}>0.05\left(\chi^{2}(8, \mathrm{~N}=264)\right.$ $=8.19, \mathrm{p}=0.41) . \mathrm{p}>0.05$ indicates that adolescent model is fit. However, the adolescent set scored low for Nagelkerke $\mathrm{R}^{2}$ and Cox and Snell's $\mathrm{R}^{2}$ with scores of 0.12 and 0.07 , respectively. The beginning block classification table 
Int. Business Manage., 6 (1): 17-21, 2012

Table 1: Logistic regression stepwise estimation: adolescent socialization types (adolescent)

\begin{tabular}{|c|c|c|c|c|c|c|}
\hline \multirow{2}{*}{$\begin{array}{l}\text { Overall model fit } \\
\text { Goodness of fit measures }\end{array}$} & \multirow[t]{2}{*}{ Values } & \multicolumn{3}{|c|}{ Sig. } & \multicolumn{2}{|r|}{$\mathrm{df}$} \\
\hline & & & & & & \\
\hline Cox and Snell $R^{2}$ & 0.070 & & & & & - \\
\hline Nagelkerke $\mathrm{R}^{2}$ & 0.120 & & & & & - \\
\hline Hosmer and Lemeshow $\left(\chi^{2}\right)$ & 8.192 & & & & & 8 \\
\hline$\underline{\text { Independent variables }}$ & B & $\mathrm{SE}$ & Wald & $\mathrm{df}$ & Sig. & Exp. (B) \\
\hline \multicolumn{7}{|l|}{ In the equation } \\
\hline Agreeableness & 0.501 & 0.220 & 5.190 & 1 & 0.023 & 1.651 \\
\hline Need for body resources & 0.490 & 0.183 & 7.167 & 1 & 0.007 & 1.632 \\
\hline Constant & -2.495 & 1.006 & 6.146 & 1 & 0.013 & 0.082 \\
\hline Independent variables & Score & \multicolumn{4}{|c|}{$\mathrm{df}$} & Sig. \\
\hline \multicolumn{7}{|l|}{ Not in the equation } \\
\hline Need for arousal & 0.182 & \multicolumn{4}{|c|}{1} & 0.670 \\
\hline Openness to experience & 0.832 & \multicolumn{4}{|c|}{1} & 0.362 \\
\hline \multirow[t]{2}{*}{ Conscientiousness } & 0.100 & & & & & 0.752 \\
\hline & \multicolumn{6}{|c|}{ Predicted group membership ${ }^{b}$ (Analy sis sample ${ }^{a}$ ) } \\
\hline Classification matrix & LoPCSO & & & & & Total \\
\hline \multicolumn{7}{|l|}{ Actual group membership } \\
\hline \multirow[t]{2}{*}{ HiPCSO } & $222(100)$ & \multicolumn{3}{|c|}{0} & & 222 \\
\hline & 42 & \multirow{2}{*}{\multicolumn{3}{|c|}{$\begin{array}{l}0 \\
(0)\end{array}$}} & & - \\
\hline$\underline{\text { LoPCSO }}$ & - & & & & & 42 \\
\hline
\end{tabular}

allows the computation of the threshold value or the cut off value. In this instance if all the data points are classified as $\mathrm{HiPCSO}$, percentage of correctly classified is $84.10 \%$. Comparing the threshold value with the overall percentage of correctly classified in the classification table after the execution of logistic regression (Table 1), the outcome reveals that the classification summaries based on original data $(84.10 \%)$ and logistic regression model $(84.105 \%)$ are the same. Even though, most of the cases fell into Highly Consumer Socialized mothers (HiPCSO) category, significant factors discerning the HiPCSOs from the Lowly Consumer Socialized mothers (LoPCSO) were identified. In this case, highly consumer socialized mothers are differentiated from the lowly consumer socialized mother by two adolescent socialization types, agreeableness $(\mathrm{B}=0.50$, Wald $=5.19$, $\mathrm{p} \leq 0.05$ ) and need for body resources ( $\mathrm{B}=0.49$, Wald $=7.17, \mathrm{p} \leq 0.05$ ).

Positive beta coefficients indicate direct relationships between the significant independents and PCSO. The more agreeable an adolescent is the more likely a mother will be consumer socialized by the adolescent. On the other hand, the more the desire of an adolescent to enhance her physical resources, i.e., improving on her physical appearance, the more likely a mother will be consumer socialized by the adolescent. Therefore, $\mathrm{H}_{\text {study }}$ is supported by the adolescent data set.

Mother on the other hand, mothers' data set produced an unfit model with all the independent variables producing insignificant results. Thus, $\mathrm{H}_{\text {study }}$ for mothers' data is not supported. From 3M Model of Motivation and Personality perspective, the elemental traits also known as adolescent socialization types in this study do differentiate between mothers who are highly socialized by their children and mothers who score low for parent consumer socialization outcome. From the adolescents' perspective, the most discerning traits that differentiate HiPCSOs from LoPCSOs are the adolescents' levels of agreeableness and need for body resources. Adolescents may think that being agreeable enhances their chances to consumer socialize their mothers where mothers in turn provide material rewards to these adolescents for their obedience. Also, need for body resource is essential to the adolescents, especially at this stage of their life. Adolescents desire to be physically attractive and maintain attractive physical appearances are of utmost importance.

Thus, by leveraging on the attractiveness of their physical outlook on their mothers, the adolescents gained body resources by influencing their mothers in product and brand selection as well as in the process of purchase decision making. In this case, the purchase of family related product or service. However, mothers' perception of PCSO is not susceptible to any of the adolescent socialization types or elemental personality traits. One possible explanation for this phenomenon is that mothers may feel that they are more empowered compared to their children in consumer related activities, i.e., leveraging on their years of parenting experience as supported by resource theory. Therefore, these findings partially support $\mathrm{H}_{\text {study }}$ of this research.

\section{CONCLUSION}

In future incorporating a triadic approach, fathermother-child or siblings dyad (sibship impact) may enable 
researchers to better capture the workings of parent consumer socialization. Replication of this study using international samples is strongly suggested. This will enable comparisons of international and local samples hence, generating a more comprehensive picture of parent consumer socialization phenomenon.

Additionally, comparison between the three major ethnic groups residing in Malaysia is also a future investigation that is called for. The incorporation of $3 \mathrm{M}$ Model of Motivation and Personality, relevant elemental traits, referred to as adolescent socialization types in this study were identified. In addition, relationship between Adolescent (ASA) and Parent Consumer Socialization Outcome (PCSO) was also identified. Whereby in the context of 3M Model, PCSO is treated as the surface trait (a category-specific disposition) representing enduring disposition to act with regard to a specific product category or a narrow domain of behavior.

This study proves that consumer socialization is applicable not only to children but also to adults whereby agreeableness and need for body resources are identified as the discerning adolescent socialization types that distinguished the highly consumer socialized mothers from the lowly consumer socialized ones.

From managerial perspective, marketers could sell family related products more efficiently by targeting children with a certain socialization type that is by projecting specific personality traits in their marketing campaign efforts. Additionally, findings of this study, reaffirms the growth of one potential market segments, the invaluable adolescent market. Rethinking on marketing campaigns, creating novel and innovative marketing campaigns are necessary to capture this segment. Marketers in turn can do more with less whereby they can capture the mothers market via their children.

\section{REFERENCES}

Allport, G.W., 1961. Pattern and Growth in Personality. Holt, Rinehart and Winston, New York, ISBN: 10: 0030108101 , Pages: 608.

Bearden, W.O. and R.L. Rose, 1990. Attention to social comparison information: An individual difference factor affecting consumer conformity. J. Consum. Res., 16: 461-471.

Bosnjak, M., M. Galesic and T. Tuten, 2007. Personality determinants of online shopping: Explaining online purchase intentions using a hierarchical approach. J. Bus. Res., 60: 597-605.
Carlson, L. and S. Grossbart, 1988. Parental style and consumer socialization of children. J. Consum. Res., 15: 77-94.

Eysenck, H.J., 1991. Dimensions of personality: 16, 5 or 3 Criteria for a taxonomic paradigm. Personality Individual Differences, 12: 773-790.

Ghani, N.H.A. and O.M. Zain, 2004. Malaysian children's attitudes towards television advertising. Young Consum. Insight Ideas Responsible Market., 5: 41-51.

Horton, R.L., 1979. Some relationships between personality and consumer decision-making. J. Market. Res., 16: 233-246.

Licata, J., J.C. Mowen, E.G. Harris and T. Brown, 2003. On the trait antecedents and outcomes of service worker job resourcefulness: A hierarchical model approach. J. Acad. Market. Sci., 31: 256-271.

McNeal, J.U., 1998. Kids as Customers: A Handbook of Marketing to Children.. Lexington Books, New York, ISBN: 9780669276275, Pages: 258.

Moschis, G.P. and G.A.J.R. Churchill, 1978. Consumer socialization: A theoretical and empirical analysis. J. Market. Res., 15: 599-609.

Moschis, G.P. and L.G. Mitchell, 1986. Television advertising and interpersonal influences on teenagers participation in family consumer decisions. Adv. Consumer Res., 13: 181-186.

Moschis, G.P., 1987. Consumer Socialization: A Lifecycle Perspective.. D.C. Heath and Company, Lexington.

Mowen, J.C., 2000. The 3M Model of Motivation and Personality: Theory and Empirical Applications to Consumer Behavior.. Kluwer Academic Publishers, Boston, ISBN: 9780792385431, Pages: 314.

Plummer, J.T., 2000. How personality makes a difference. J. Advertis. Res., 40: 79-84.

Radke-Yarrow, M., C. Zahn-Waxler and M. Chapman, 1983. Children's Prosocial Dispositions and Behavior. In: Socialization, In: Personality and Social Development, Hetherington, E.M. (Ed.). John Wiley and Sons, New York, pp: 469-546.

Swinyard, W.R. and C.P. Sim, 1987. Perception of children's influence on family decision processes. J. Consum. Market., 4: 25-38.

Viswanathan, M., T.L. Childers and E.S. Moore, 2000. The measurement of intergenerational communication and influence on consumption: Development, validation and cross-cultural comparison of the IGEN scale. J. Acad. Market. Sci., 28: 406-424.

Ward, S., 1974. Consumer socialization. J. Consum. Res., 1: $1-16$.

Webster, C., 2000. Is spousal decision making a culturally situated phenomenon. Psychol. Market., 17: 1035-1058. 